\title{
Selective Ring Opening Allene Metathesis: Polymeriza- tion or Ruthenium Vinylidene Formation
}

\author{
William J. Neary ${ }^{*}$, Yunyan Sun, Jeffrey S. Moore* \\ Beckman Institute for Advanced Science and Technology, University of Illinois at Urbana-Champaign, Urbana, Illinois \\ 61801, United States; Department of Chemistry, University of Illinois at Urbana-Champaign, Urbana, Illinois 61801, United \\ States
}

\begin{abstract}
Selective ring-opening allene metathesis polymerization (ROAlMP) and ruthenium vinylidene formation from 1,2cyclononadiene (1) by simple catalyst selection are discussed. Grubbs second generation catalyst (G2) favors the formation of an alkylidene leading to the ROAlMP of (1). Grubbs first generation catalyst (G1) favors vinylidene formation and prevents the homopolymerization of (1) even at elevated temperatures. Isolation and characterization of poly(1) by NMR analysis and MALDITOF confirms the generation of a well-defined polyallene that exhibits good thermal stability $\left(T_{\mathrm{D}}\right.$ ca. $\left.400{ }^{\circ} \mathrm{C}\right)$ and fluorescent properties. Ring-opening metathesis polymerization (ROMP) of a high strained norbornene derivative (NBE- $\left.{ }^{\mathrm{i}} \mathrm{Pr}\right)$ at $80{ }^{\circ} \mathrm{C}$ using the ruthenium vinylidene generated from (1) is also investigated. The discovery of ROAlMP allows for the simple accesses of welldefined polyallenes from commercially available catalysts and will ultimately guide structure-property determinations of polyallenes.
\end{abstract}

\section{Introduction:}

Allenes, the simplest class of cumulenes, were discovered over a century ago. ${ }^{1}$ They have become a staple in the modern organic chemists toolbox as a direct result of the myriad of chemical transformations made possible by their unique structure $^{2,3}$ and can be found in over 150 natural products, pharmaceuticals $^{4}$, and even elastomers. ${ }^{5}$ From a materials context, they are known as "carbon-rich, shape-persistent, axially chiral scaffolds". 6 Yet, their exploration in polymers is limited. The lack of employment of allenes in soft materials chemistry stems from a scarcity of polymerization techniques that preserve the functionality of allenes and as a consequence, the materials produced generally lack functional utility. ${ }^{7}$ A handful of reports that successfully incorporate allenes into the repeating structure of a material are known, however, these reports typically require specialized catalyst systems and only produce oligomers. $^{8-12}$

An alternative route to polyallenes was recently demonstrated via post-polymerization transformation. ${ }^{13}$ In the report, the authors carried out a two-step Skattebøl rearrangement on cispoly(norbornene) resulting in allene incorporation at varying percentages $(20-95 \%)$ along the backbone. While this method represents a simplistic general route to polyallenes, it does come with shortcomings as pointed out by the authors. The synthetic methodology relies upon a cis olefin geometry that can only be prepared through the use of a specialized Zselective catalyst. On top of this, the incorporation of allenes occur in a random and non-quantitative manner, which may limit its application/scope. A polymerization that retains the allene functionality during the polymerization and utilizes commercially available catalysts is a potentially useful methodology for the generation of polyallenes. A polymerization of this sort would increase the tuneability and accessibility of polyallenes, ultimately allowing for structure-property determinations.

Metathesis based polymerizations that utilize Grubbs catalyst such as $\mathrm{ROMP}^{14}$ and acyclic diene metathesis polymerization (ADMET) $)^{15}$, represent two of the most powerful polymerization techniques investigated over the past two decades. This is in part due to the benchtop stability and high functional group tolerance of Grubbs catalyst. With the emergence of alternative metathesis polymerizations such as cyclopolymerizations $^{16}$, metallotropy ${ }^{17}$, and enyne metathesis polymerizations $^{18}$, its surprising that the polymerization of allenes, which are known to be reactive with Grubbs catalyst, remain unexplored. ${ }^{19}$

Scheme 1. Allene Metathesis

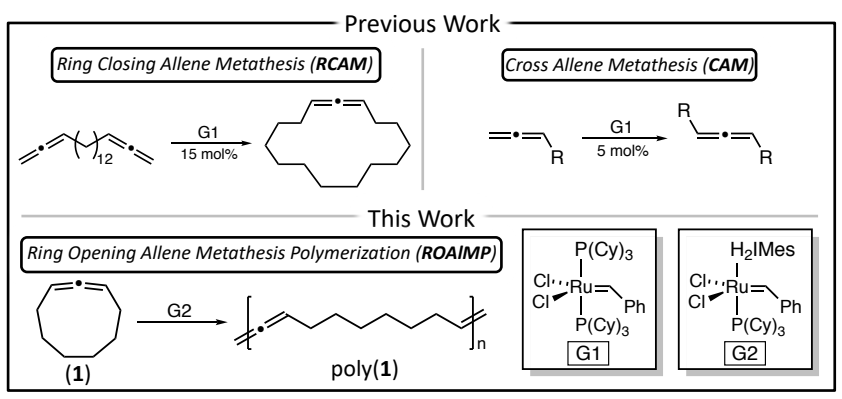

The utilization of allenes in metathesis is surprisingly limited (Scheme 1). The first documented report on allene metathesis was in 2000 in which terminal mono-substituted allenes underwent cross-allene metathesis (CAM) with Grubbs first generation catalyst (G1). ${ }^{20}$ While not all derivatives underwent successful/productive metathesis, this was the first account showing that allenes behave analogously to alkenes in 


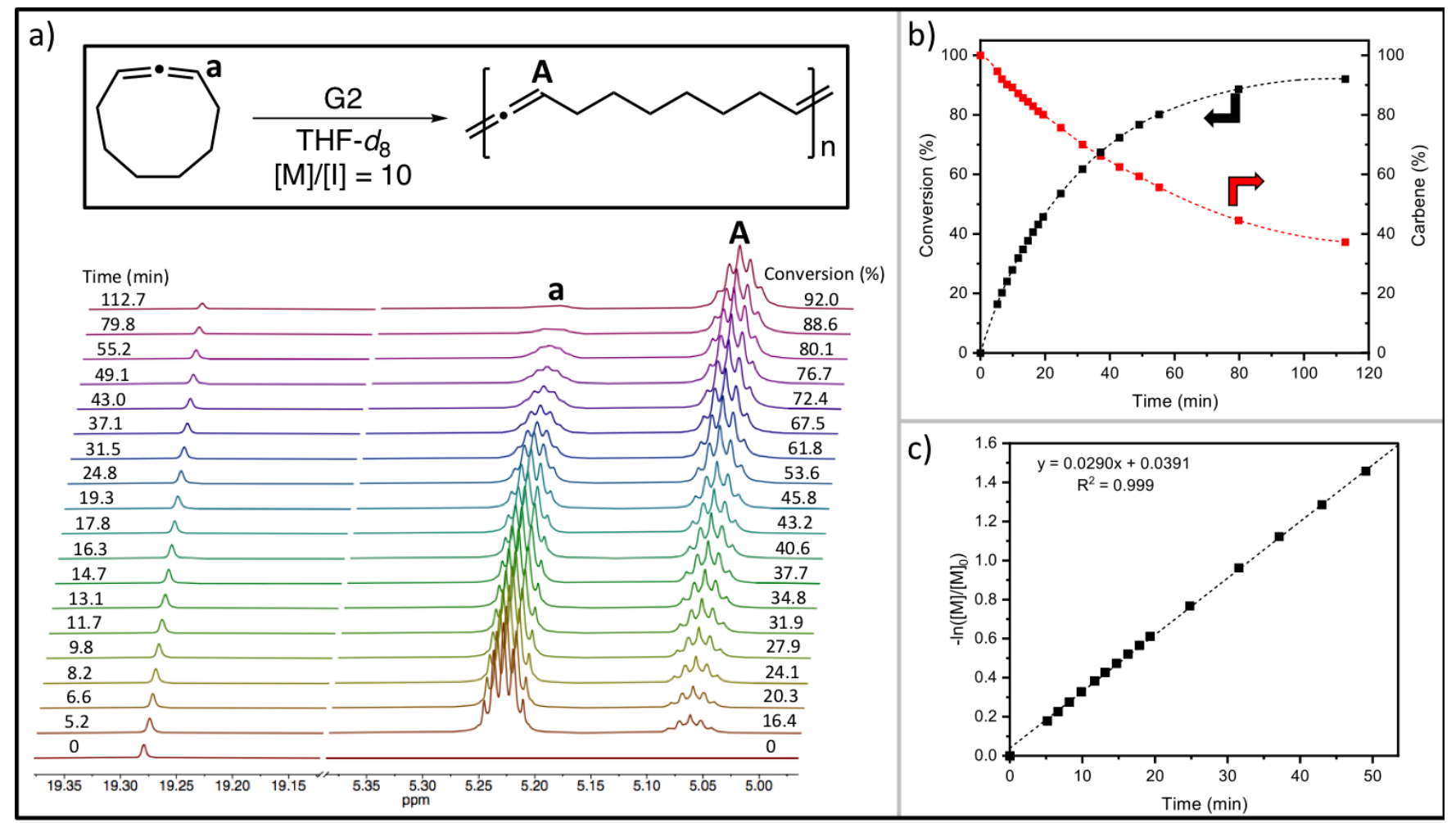

Figure 1. a) Stacked ${ }^{1} \mathrm{H}-\mathrm{NMR}$ spectra monitoring the formation of poly(1) in THF- $d_{8}$ at $25^{\circ} \mathrm{C}$. b) Residual carbene and polymerization conversion vs. time. c) Linear plot of $-\ln \left([\mathrm{M}] /[\mathrm{M}]_{0}\right)$ vs. time showing first order kinetics.

cross metathesis. It was later shown that macrocyclic allenes $(\mathrm{n}=15-19)$ could be accessed by ring closing allene metathesis (RCAM) also utilizing G1, albeit in low yields. ${ }^{21}$ These two accounts represent the only reports of allene metathesis with Grubbs catalyst in literature but highlight their potential utility. Despite the dearth of precedent, we hypothesized that the ring-opening metathesis polymerization of cyclic allenes yields polyallenes, analogous to the generation of polyolefins from ROMP. Successful polymerization would allow for the precise installment of allenes into the repeating structure of materials without the use of complex catalyst systems or postpolymerization modifications. Herein, we report the ring opening allene metathesis polymerization (ROAlMP) of a cyclic allene and discuss the general features of this polymerization.

\section{Results and Discussion:}

ROMP is driven by the release of ring-strain of its cyclic olefin monomer, so it stands to reason that a similar requirement exists for the opening of cyclic allenes. Unfortunately, unlike strained cyclic alkenes, cyclic allenes (ring size $\leq 8$ ) are thermally unstable and dimerize rapidly under ambient conditions, making them impractical for polymerization. ${ }^{22}$ However, it has been shown that medium sized rings (ring size $\geq 9$ ), such as 1,2-cyclononadiene (1), are accessible on the gram-scale via the Doering-LaFlamme-Skattebøl rearrangement and are stable under ambient conditions (dimerizing at ca. $100{ }^{\circ} \mathrm{C}$ ). ${ }^{23}$ Being the smallest thermally stable cyclic allene available, we began by investigating the ring-strain of (1) to determine if it was sufficiently strained for polymerization. An isodesmic reaction analysis, analogous to ROMP ring-strain calculations, was used to determine the ring-strain of the system (Figure
S8) ${ }^{24}$ Consistent with a prior report, (1) exhibits $12.7 \mathrm{kcal} / \mathrm{mol}$ of ring-strain, a value between cis and trans-cyclononene. ${ }^{25}$ Larger rings, such as 1,2-cyclodecadiene were also investigated and showed a comparable ring strain $(15.9 \mathrm{kcal} / \mathrm{mol})$. However, for the focus of this report, we set aim on the polymerization of (1) due to its facile accessibility in grams scale quantities compared to 1,2-cyclodecadiene.

Initial polymerization investigations of (1) were conducted with Grubbs second generation catalyst (G2). As seen in Figure 1 , at a monomer to initiator ratio $\left([\mathrm{M}]_{0} /[\mathrm{I}]_{0}\right)$ of 10 with $[\mathrm{M}]_{0}=1 \mathrm{M}$ in THF- $d_{8}$ at $25{ }^{\circ} \mathrm{C}$, a disappearance of the olefinic signal $(\delta 5.23)$ and the concomitant appearance of a new upfield peak at $\delta 5.06$ (A) was observed via ${ }^{1} \mathrm{H}-\mathrm{NMR}$. After 2 hours, the material reached $92 \%$ conversion with $37 \%$ residual carbene (Figure 1b). The polymerization showed first-order kinetics with respect to monomer concentration (Figure 1c) and exhibited a relatively slow propagation $\left(k_{\mathrm{obs}}=0.0290 \mathrm{~min}^{-}\right.$ $\left.{ }^{1}\right)$. To see if the use of a coordinating solvent had an effect on the polymerization, the polymerization was repeated in toluene- $d_{8}$. To our surprise, the polymerization in toluene- $d_{8}$ proceeded $3 \times$ slower $\left(k_{\text {obs }}=0.0095 \mathrm{~min}^{-1}\right)$ than THF- $d_{8}$, leading to lower conversions $(60 \%)$ over a longer reaction time $(2.5$ hours) (see Figures S9-11). The use of THF as a weakly coordinating ligand has been used advantageously in prior studies to increase the stability of propagating carbenes ${ }^{26}$; however, no indication of a new THF-alkylidene complex was observed and the stability of the carbene was only marginally improved in THF- $d_{8}$ compared to toluene- $d_{8}(81 \%$ vs. $75 \%$ respectively after ca.17.5 minutes). 


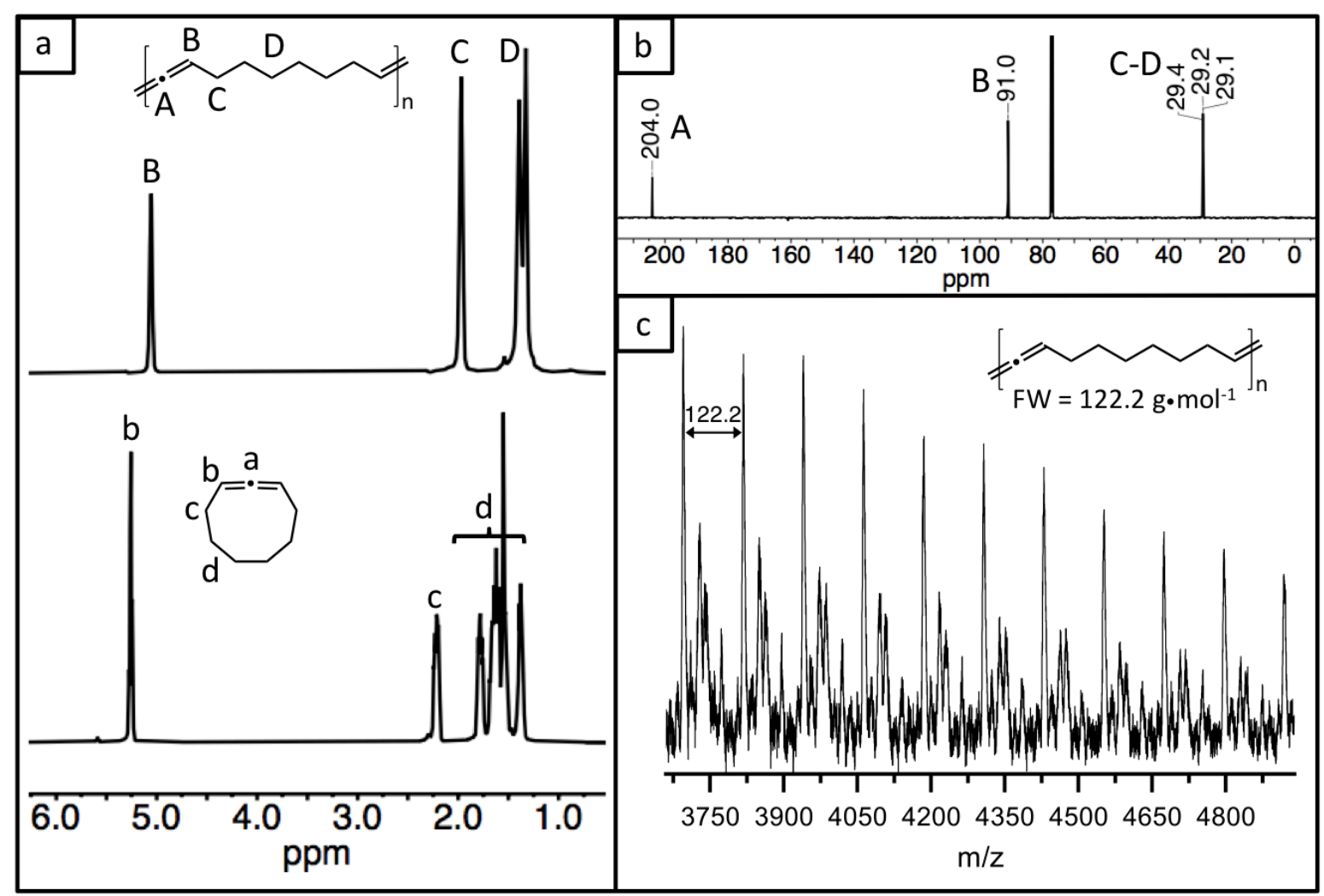

Figure 2. a) Stacked ${ }^{1} \mathrm{H}-\mathrm{NMR}$ spectra of (1) and poly(1) in $\mathrm{CDCl}_{3}\left(25^{\circ} \mathrm{C}\right)$. b) ${ }^{13} \mathrm{C}-\mathrm{NMR}$ of poly(1) in $\mathrm{CDCl}{ }_{3}\left(25^{\circ} \mathrm{C}\right)$. c) $\mathrm{MALDI}-$ TOF of poly(1) with the correct repeating unit mass observed.

While it seems unlikely that THF is behaving in this manner, due to the improved propagation rates, THF was chosen as our solvent of choice.

Confirmation of the proposed constitutional repeating unit (CRU) of poly(1) was obtained by NMR characterization. Poly(1) was first isolated by precipitation into cold methanol $\left(-78^{\circ} \mathrm{C}\right)$ and vacuum dried before characterization. Figure 2a shows stacked spectra of the monomer and isolated material in $\mathrm{CDCl}_{3}$. Integrations of the obtained spectra along with COSY correlations match the proposed CRU (Figure S12-13). Gratifyingly, ${ }^{13} \mathrm{C}$-NMR (Figure 2b) showed the appearance of the central $s p$-hybridized allene carbon at $\delta_{\mathrm{C}} 204$, slightly upfield from that observed in (1) at $\delta_{\mathrm{C}} 206$. MALDI-TOF of a larger isolated poly(1) was also conducted to confirm the repeating structure and as can be seen in Figure 2c, a repeating structure on average of $122.2 \mathrm{~g} \cdot \mathrm{mol}^{-1}$ was observed, matching the predicted CRU.

With evidence of a successful homopolymerization via G2, we screened various polymerization conditions, starting with catalyst loadings, and monitored their effect on the polymerization. Catalyst loadings from 4.0-0.5\% ( $[\mathrm{M}]_{0} /[\mathrm{I}]_{0}=25-$ 200) were attempted and had a dramatic effect on the polymerization conversion (Table 1). Highest conversions $(52.6 \%)$ were obtained at high catalyst loadings $\left([\mathrm{M}]_{0} /[\mathrm{I}]_{0}=25\right)$ whereas only low conversions $(10.2 \%)$ were obtained at lower loadings $\left([\mathrm{M}]_{0} /[\mathrm{I}]_{0}=200\right)$. This dependency of catalyst loading is attributed to the instability of the propagating species, resulting in low catalyst turnover.

Initial monomer concentration, which can have large effects depending upon the strain of the monomer, was next ivestigated. ${ }^{27}$ Interestingly, conversions were not particularly sensitive to monomer concentrations, as ca. $48 \%$ conversion was obtained over the range of concentrations tested $(3.0-0.5 \mathrm{M})$. However, decreasing concentration did lead to increasing $Ð$
(1.89 - 2.78) which is indicative of intrachain backbiting where higher $[\mathrm{M}]_{0}$ help to increase propagation rates relative to backbiting, leading to lower $\oslash .^{28}$

Lastly, we screened reaction temperatures from $0-50^{\circ} \mathrm{C}$. This range covers conventional reaction temperatures used in ROMP, and is lower than the boiling point of THF. At a constant $[\mathrm{M}]_{0}$ and catalyst loading, the polymerization was highly sensitized to reaction temperatures, with a $50{ }^{\circ} \mathrm{C}$ change leading to a $72 \%$ conversion increase. Surprisingly, elevated temperatures led to the highest conversions, contrary to what is commonly observed in most ROMP systems. We hypothesize that elevated temperatures allow the system to combat the slow propagation alongside the relatively unstable propagating species. Although elevated temperatures are generally deleterious to metathesis, serving to shorten catalyst lifetimes while increasing entropic penalties associated with the polymerization $^{29}$, they have been successfully employed in systems where increased catalytic activity are needed or slow propagation is observed. $^{30}$ At elevated temperatures, increased conversions compared to room temperature trials were obtained (44\% vs. $81 \%$ at $\left([\mathrm{M}]_{0} /[\mathrm{I}]_{0}=50\right)$. Molecular weights remained unchanged, likely due to increased chain transfer.

After the screening and optimization of polymerization conditions with G2, we next studied the effects of catalyst structure on polymerization. Differences in Grubbs catalyst structure have interestingly shown selectivity difference towards allenes, alkenes, and alkynes. ${ }^{19}$ Second generation catalysts (G2 and Hoveyda-Grubbs second generation (HG2)) show a preference towards alkynes over allenes and alkenes, whereas first generation species (Grubbs first generation (G1) and Hoveyda-Grubbs first generation (HG1)) show a selectivity of allenes over alkenes and alkynes, with G1 showing an order of magnitude higher selectivity of allenes over alkenes. Additionally, the prior CAM and RCAM reports both successfully 
Table 1. Screening of Polymerization Conditions for poly(1) with G2.

\begin{tabular}{|cccccccc|}
\hline$[\mathrm{M}] /[\mathrm{I}]$ & {$[\mathrm{M}]_{0}$} & Temp. $\left({ }^{\circ} \mathrm{C}\right)$ & Time $(\mathrm{h})$ & Conversion $(\%)^{\mathrm{a}}$ & {$[\mathrm{M}]_{\mathrm{n}, \text { Theo. }}(\mathrm{kDa})^{\mathrm{b}}$} & $\mathrm{M}_{\mathrm{n}}(\mathrm{kDa})^{\mathrm{c}}$ & $D^{c}$ \\
\hline 25 & 3 & 25 & 2 & 52.6 & 1.6 & 8.8 & 2.48 \\
50 & 3 & 25 & 2 & 44.4 & 2.7 & 13.7 & 1.89 \\
75 & 3 & 25 & 2 & 24.6 & 2.3 & 11.5 & 1.91 \\
100 & 3 & 25 & 2 & 17.3 & 2.1 & 11.8 & 1.82 \\
150 & 3 & 25 & 2 & 13.8 & 2.5 & 11.0 & 1.83 \\
200 & 3 & 25 & 2 & 10.2 & 2.5 & 11.0 & 1.79 \\
\hline 50 & 2 & 25 & 2 & 48.5 & 3.0 & 9.9 & 2.07 \\
50 & 1 & 25 & 2 & 51.5 & 3.1 & 5.8 & 2.65 \\
50 & 0.5 & 25 & 2 & 48.4 & 3.0 & 3.8 & 2.78 \\
\hline 50 & 1 & 0 & 3 & 9.1 & 0.6 & 8.3 & 1.92 \\
50 & 1 & 50 & 1 & 81.0 & 4.9 & 4.6 & 4.34 \\
\hline 100 & 1 & 50 & 1 & 39.4 & 4.8 & 10.8 & 1.80 \\
250 & 1 & 50 & 1 & 23.1 & 7.1 & 10.1 & 1.82 \\
\hline
\end{tabular}

a) Conversions determined by ${ }^{1} \mathrm{H}-\mathrm{NMR}$ analysis in $\mathrm{CDCl}_{3}\left(25^{\circ} \mathrm{C}\right) .{ }^{\text {b) }}$ Determined by $([\mathrm{M}] /[\mathrm{I}]]^{*}$ conversion $) * \mathrm{FW}_{1} \cdot{ }^{\mathrm{c})} \mathrm{Determined} \mathrm{by}$ SEC (RI) in THF based off a 12 point conventional column calibration using narrowly dispersed polystyrene standards.

employed G1 as their catalyst choice.

To see if the increased allene selectivity of G1 was beneficial for ROAlMP, (1) was subjected to $\mathrm{G} 1$ at $[\mathrm{M}]_{0} /[\mathrm{I}]_{0}=10$, $[\mathrm{M}]_{0}=1 \mathrm{M}$ in toluene- $d_{8}$. Unfortunately, after similar reaction times as G2 trials, no polymerization had occurred. In contrast to $\mathrm{G} 2$ trials that showed a slow disappearance of the alkylidene peak with increasing conversions, a complete and rapid disappearance of the alkylidene peak $(\delta 20.5)$ occurred in 5 minutes. To understand why G1 was not reactive towards ROAlMP, we investigated the possible mechanistic pathways of the reaction.

Scheme 2 shows the two possible pathways that lead to the same CRU. In pathway 1, the catalyst undergoes 2,1-insertion, leading to the generation of a ruthenium vinylidene as the catalytic species. First generation ruthenium vinylidenes have been generated through multiple synthetic pathways, and show extremely limited reactivity towards metathesis compared to their second-generation counterparts. ${ }^{31}$ In pathway 2, 1,2insertion of the catalyst leads to a standard alkylidene catalytic species. Insight into the mechanistic pathway from previous CAM and RCAM reports were indeterminate (Figure S23).

The reaction pathway was elucidated by ${ }^{13} \mathrm{C}$ NMR analysis in comparison to previously reported first generation vinylidene species. As seen in Figure 3, ${ }^{13} \mathrm{C}$ NMR spectra of the $[\mathrm{M}]_{0} /[\mathrm{I}]_{0}=10$ trials show a clear difference between catalysts. For G2, an alkylidene peak at $\delta_{\mathrm{C}} 295$ was observed as well as both allene peaks from unconsumed monomer and polymer,

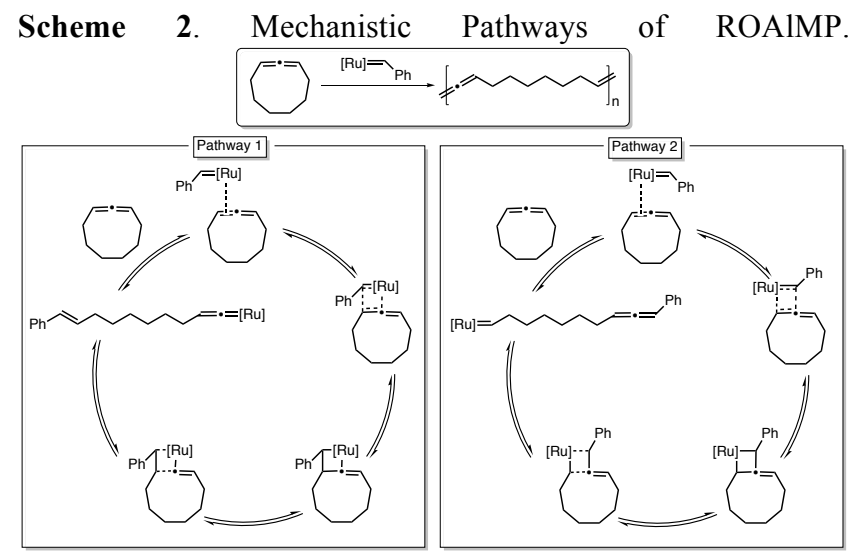

indicating pathway 2 is dominant for G2. For G1, a new peak at $\delta 336 \mathrm{ppm}$ was observed, similar to other first generation ruthenium vinylidene species. ${ }^{32}$ Further confirmation of a ruthenium vinylidene came from ESI-HRMS of a $[\mathrm{M}]_{0} /[\mathrm{I}]_{0}=1$ trial that showed a m/z at 909.4908 (909.4937 calc.) indicative of the $[\mathrm{M}-\mathrm{Cl}]^{+\bullet}$ commonly observed in the ESI-MS of Grubbs catalyst. $^{33}$ This study demonstrated that simple variations of the catalyst structure selectively lead to alternative mechanistic pathways for G1 and G2.

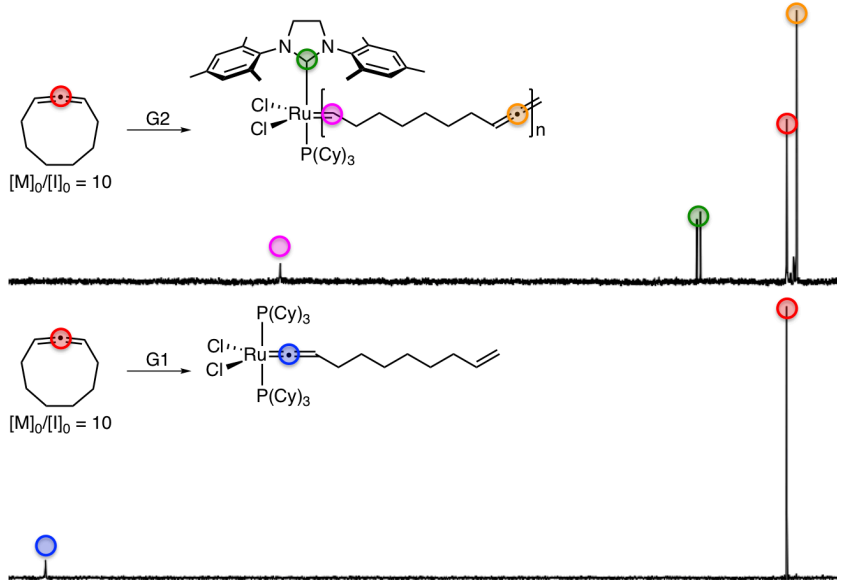

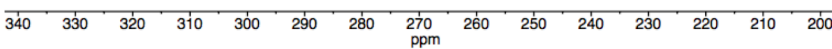

Figure 3. Stacked ${ }^{13} \mathrm{C}-\mathrm{NMR}$ spectra in toluene- $d_{8}\left(25^{\circ} \mathrm{C}\right)$ of $[\mathrm{M}] /[\mathrm{I}]=10$ trials of (1) with (bottom) G1 and (top) G2.

While G1 led to the formation of a ruthenium vinylidene, this new catalyst species did not result in productive polymerization of (1) at room temperature. Given that first generation vinylidenes have shown limited reactivity in olefin metathesis, we hypothesized that elevated temperatures would increase the activity of the ruthenium vinylidene towards ROAlMP. Trials with $\mathrm{G} 1$ at $[\mathrm{M}]_{0} /[\mathrm{I}]_{0}=10$ were repeated and subsequently heated to $50{ }^{\circ} \mathrm{C}$ upon the complete formation of the vinylidene at room temperature and subsequently monitored via ${ }^{1} \mathrm{H}$ NMR. Disappearance of monomer over an hour was observed along with the generation two new downfield peaks at $\delta 5.8$ and 5.6. Upon triple precipitation into $\mathrm{MeOH}$ at $-78{ }^{\circ} \mathrm{C}$, both downfield peaks disappeared and only aliphatic protons were 
observed (Figure S1-2). No allene signal was observed in ${ }^{13} \mathrm{C}$ NMR of the isolated material and we are currently unable to assign a correct microstructure for this polymer.

Although the homopolymerization of (1) was not viable with G1, we hypothesized that the vinylidene is active towards highly strained species such as norbornene. Generation of the ruthenium vinylidene was repeated, this time with only slight excess of (1). Upon complete disappearance the alkylidene signal, 10 equiv of NBE- ${ }^{i}$ Pr was added and monitored via ${ }^{1} \mathrm{H}$ NMR (Figure 4). Unfortunately, no polymerization of
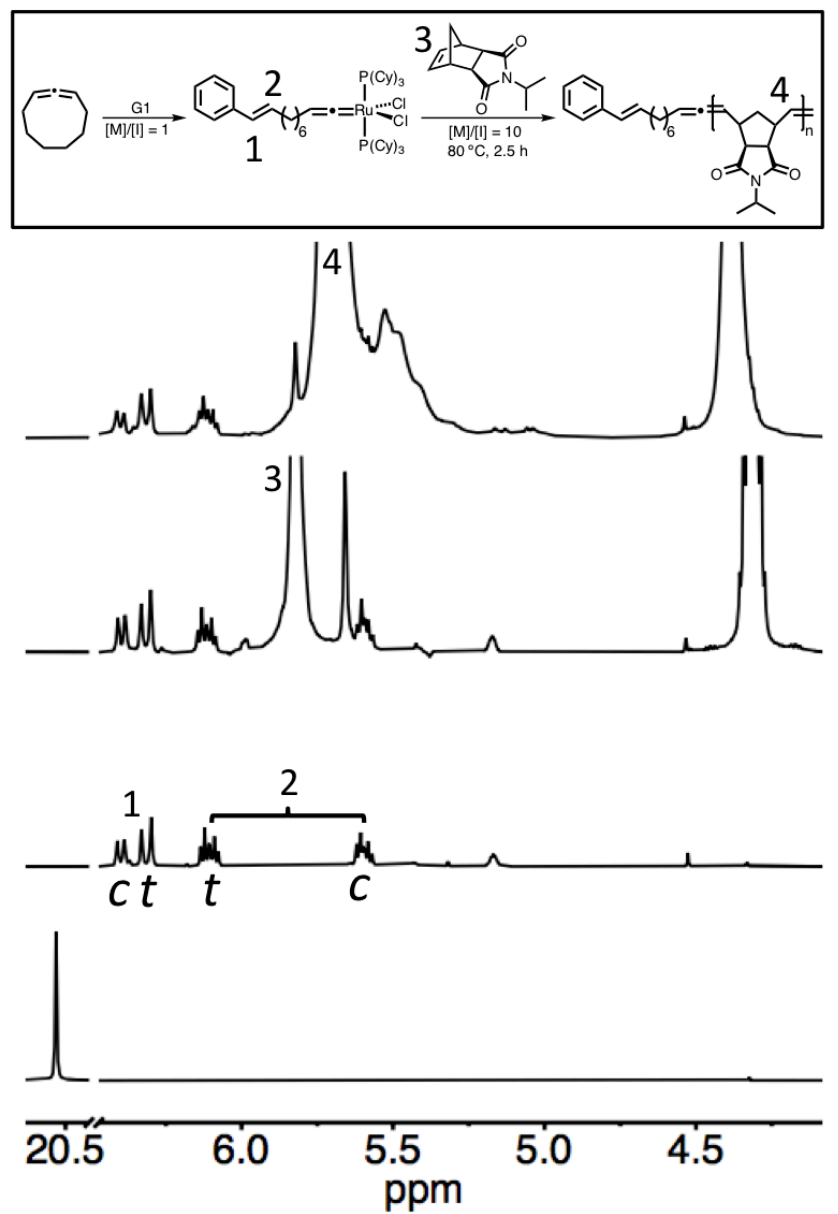

Figure 4. Stacked ${ }^{1} \mathrm{H}-\mathrm{NMR}$ spectra in toluene- $d_{8}$ of polymerization of NBE- ${ }^{i}$ Pr using a ruthenium vinylidene. (Bottom) G1 at $\mathrm{t}=0 \mathrm{~min}$. (Middle bottom) Ruthenium vinylidene. $c$ and $t$ stand for cis and trans, respectively. (Middle top) Ruthenium vinylidene and $\mathrm{NBE}-{ }^{i} \mathrm{Pr}$ at $25^{\circ} \mathrm{C}$. (Top) Poly(NBE- ${ }^{i} \mathrm{Pr}$ ) after $2.5 \mathrm{~h}$ at $80^{\circ} \mathrm{C}$ with ruthenium vinylidene.

NBE- ${ }^{i}$ Pr was observed at room temperature, even after extended reaction times. However, upon heating the reaction mixture to $80{ }^{\circ} \mathrm{C}$ for 2.5 hours, near quantitative conversion to Poly(NBE- ${ }^{\mathrm{i}} \mathrm{Pr}$ ) was obtained. The reformation of an alkylidene was not observed after 2.5 hours which is likely caused by the limited lifetime of the catalyst at elevated temperature. ${ }^{29}$ Although this process is not controlled, it serves as a proof of concept that the selective formation of a ruthenium vinylidene from G1 serves to catalyze highly strained systems.

Thermal and photophysical properties of poly(1) were also preliminarily investigated. Thermogravimetric analysis (TGA) of the isolated material under nitrogen showed good thermal stability, with $5 \%$ mass loss occurring at $400{ }^{\circ} \mathrm{C}$ (Figure S18). This value is similar to decomposition temperatures observed for the previously produced polyallene from cis- poly(norbornene). ${ }^{13}$ Differential scanning calorimetry (DSC) from $-60-100{ }^{\circ} \mathrm{C}$ at both 10 and $20^{\circ} \mathrm{C} \cdot \mathrm{min}^{-1}$ did not show any indication of a glass transition temperature $\left(T_{\mathrm{g}}\right)$ (Figure S19) even though poly(1) shares a similar microstructure to poly(cyclooctene), whose $T_{\mathrm{g}}$ is $-60^{\circ} \mathrm{C}$. Photophysical properties of our poly(1) sample were also investigated with both $\mathrm{UV}-\mathrm{V}$ is and fluorometry experiments. Similar to prior studies, broad emissions $\left(\lambda_{\mathrm{EM}}=360-660 \mathrm{~nm}\right)$ at $1.0 \mathrm{mg} \bullet \mathrm{mL}^{-1}$ in THF of poly(1) were observed, consistent with recently reported allene-containing polymers (Figure S20). ${ }^{13}$

\section{Conclusion:}

Ring opening allene metathesis of a cyclic allene is reported for the first time using G2. The polymerization exhibited increased conversions at elevated temperatures, catalyst loadings, and when conducted in THF. Spectral characterization confirms the generation of an allene on every $8^{\text {th }}$ carbon backbone, leading to the first well-defined polyallene system. The materials show good thermal stability and are a potentially useful reactive scaffold for post-polymerization modifications in the future. G1 was shown to selectively form a ruthenium vinylidene that exhibited low catalytic activity. Turnover of the species was demonstrated at elevated temperatures with the use of strained cyclic alkenes. Gaining control of the ROAIMP and the vinylidene are important next steps needed to maximize the utility of these methods in the future.

\section{ASSOCIATED CONTENT}

\section{Supporting Information}

The Supporting Information is available free of charge on the ACS Publications website.

Synthesis and characterization of compounds (PDF)

\section{AUTHOR INFORMATION}

\section{Corresponding Author}

* William J. Neary - Department of Chemistry, University of Illinois at Urbana-Champaign, Urbana, Illinois 61801, United States

Email:wneary@illinois.edu

* Jeffrey S. Moore - Beckman Institute for Advanced Science and Technology, University of Illinois at Urbana-Champaign, Urbana, Illinois 61801, United States; Department of Chemistry, University of Illinois at Urbana-Champaign, Urbana, Illinois 61801, United States

Email: jsmoore@illinois.edu

\section{Authors}

Yunyan Sun - Department of Chemistry, University of Illinois at Urbana-Champaign, Urbana, Illinois 61801, United States

\section{ACKNOWLEDGMENT}

Mechanistic investigations were supported by the U.S. Department of Energy, Office of Basic Energy Sciences, Division of Materials Sciences and Engineering under Award\# DE-FG0207ER46471 and exploration of new metathesis-active monomers were supported by U.S. Department of Defense by a MURI (Multi-University Research Initiative) through the Army Research Office (ARO) through Award W911NF-16-1-0372. 


\section{REFERENCES}

(1) Burton, B. S.; von Pechmann, H. Ueber die Einwirkung von Chlorphosphor auf Acetondicarbonsäureäther. Berichte der deutschen chemischen Gesellschaft 1887, 20, 145-149.

(2) Alcaide, B.; Almendros, P. Progress in allene chemistry. Chem. Soc. Rev. 2014, 43, 2886-2887.

(3) Norbert Krausa, A. S. K. H. Modern Allene Chemistry; Wiley, 2004; Vol. 2.

(4) Hoffmann-Röder, A.; Krause, N. Synthesis and Properties of Allenic Natural Products and Pharmaceuticals. Angew. Chem., Int. Ed. 2004, 43, 1196-1216.

(5) Yamauchi, A.; Shirai, A.; Kawabe, K.; Iwamoto, T.; Wakiya, T.; Nishiyama, H.; Inagi, S.; Tomita, I. Well-defined polymer microspheres formed by living dispersion polymerization: precisely functionalized crosslinked polymer microspheres from monomers possessing cumulated double bonds. NPG Asia Mater. 2016, 8, e307-e307.

(6) Rivera-Fuentes, P.; Diederich, F. Allenes in Molecular Materials. Angew. Chem., Int. Ed. 2012, 51, 2818-2828.

(7) Mitchell, S. M.; Niradha Sachinthani, K. A.; Pulukkody, R.; Pentzer, E. B. 100th Anniversary of Macromolecular Science Viewpoint: Polymerization of Cumulated Bonds: Isocyanates, Allenes, and Ketenes as Monomers. ACS Macro Lett. 2020, 9, 1046-1059.

(8) Hasegawa, M.; Endo, J.; Iwata, S.; Shimasaki, T.; Mazaki, Y. Chiroptical properties of 1,3-diphenylalleneanchored tetrathiafulvalene and its polymer synthesis. Beilstein J. Org. Chem. 2015, 11, 972-979.

(9) Hiroki, K.; Kikuchi, Y.; Kijima, M. Synthesis and properties of novel acid-sensitive conjugated allene polymers. Synth. Met. 2003, 135-136, 389-390.

(10) Kijima, M.; Kinoshita, I.; Shirakawa, H. Syntheses and properties of conjugated polymers with cumulenic bond in the main chain. Synth. Met. 1999, 101, 145-148.

(11) Hiroki, K.; Kijima, M. Synthesis and properties of conjugated copolymer having alternate structure of diphenylanthracene and allene. Chem. Lett. 2005, 34, 942-943.

(12) Kijima, M.; Hiroki, K.; Shirakawa, H. The First Conjugated Allene Polymer. Macromol. Rapid Commun. 2002, 23, 901-904.

(13) Galan, N. J.; Brantley, J. N. General Access to AlleneContaining Polymers Using the Skattebøl Rearrangement. ACS Macro Lett. 2020, 9, 1662-1666.

(14) Bielawski, C. W.; Grubbs, R. H. Living ring-opening metathesis polymerization. Prog. Polym. Sci. 2007, 32, 1-29.

(15) Atallah, P.; Wagener, K. B.; Schulz, M. D. ADMET: The Future Revealed. Macromolecules 2013, 46, 4735-4741.

(16) Peterson, G. I.; Yang, S.; Choi, T.-L. Synthesis of Functional Polyacetylenes via Cyclopolymerization of Diyne Monomers with Grubbs-type Catalysts. Acc. of Chem. Res. 2019, 52, 994-1005.

(17) Kang, C.; Kwon, S.; Sung, J.-C.; Kim, J.; Baik, M.-H.; Choi, T.-L. Living Metathesis and Metallotropy Polymerization Gives Conjugated Polyenynes from Multialkynes: How to Design Sequence-Specific Cascades for Polymers. J. Am. Chem. Soc. 2018, 140, 16320-16329.

(18) Fu, L.; Sui, X.; Crolais, A. E.; Gutekunst, W. R. Modular Approach to Degradable Acetal Polymers Using Cascade Enyne Metathesis Polymerization. Angew. Chem., Int. Ed. 2019, 58, 15726-15730.

(19) Kim, K. H.; Ok, T.; Lee, K.; Lee, H.-S.; Chang, K. T.; Ihee, H.; Sohn, J.-H. Quantitative Catalyst-Substrate
Association Relationships between Metathesis Molybdenum or Ruthenium Carbene Complexes and Their Substrates. J. Am. Chem. Soc. 2010, 132, 12027-12033.

(20) Ahmed, M.; Arnauld, T.; Barrett, A. G. M.; Braddock, D. C.; Flack, K.; Procopiou, P. A. Allene Cross-Metathesis: Synthesis of 1,3-Disubstituted Allenes. Org. Lett. 2000, 2, 551-553.

(21) Janßen, C. E.; Krause, N. Studies on the Synthesis of Macrocyclic Allenes by Ring Closing Metathesis and Doering-Moore-Skattebøl Reaction. Eur. J. Org. Chem. 2005, 2005, 2322-2329.

(22) Kawase, T. Product class 3: cyclic allenes. Sci. Synth. 2007, 44, 395-449.

(23) Galan, N. J.; Burroughs, J. M.; Maroon, C. R.; Long, B. K.; Brantley, J. N. Vinyl-addition polymerizations of cycloallenes: synthetic access to congeners of cyclic-olefin polymers. Polym. Chem. 2020, 11, 5578-5581.

(24) Hejl, A.; Scherman, O. A.; Grubbs, R. H. RingOpening Metathesis Polymerization of Functionalized LowStrain Monomers with Ruthenium-Based Catalysts. Macromolecules 2005, 38, 7214-7218.

(25) Daoust, K. J.; Hernandez, S. M.; Konrad, K. M.; Mackie, I. D.; Winstanley, J.; Johnson, R. P. Strain Estimates for Small-Ring Cyclic Allenes and Butatrienes. J. Org. Chem. 2006, 71, 5708-5714.

(26) Kang, E.-H.; Lee, I. S.; Choi, T.-L. Ultrafast Cyclopolymerization for Polyene Synthesis: Living Polymerization to Dendronized Polymers. J. Am. Chem. Soc. 2011, 133, 11904-11907.

(27) Neary, W. J.; Kennemur, J. G. Polypentenamer Renaissance: Challenges and Opportunities. ACS Macro Lett. 2019, 8, 46-56.

(28) Mulhearn, W. D.; Register, R. A. Synthesis of NarrowDistribution, High-Molecular-Weight ROMP Polycyclopentene via Suppression of Acyclic Metathesis Side Reactions. ACS Macro Lett. 2017, 112-116.

(29) Jawiczuk, M.; Marczyk, A.; Trzaskowski, B. Decomposition of ruthenium olefin metathesis catalyst. Catalysts 2020, 10, 887.

(30) Kang, C.; Jung, K.; Ahn, S.; Choi, T.-L. Controlled Cyclopolymerization of 1,5-Hexadiynes to Give Narrow Band Gap Conjugated Polyacetylenes Containing Highly Strained Cyclobutenes. J. Am. Chem. Soc. 2020, 142, 17140-17146.

(31) Dragutan, I.; Verpoort, F.; Dragutan, V.; Drozdzak, R. In Metathesis Chemistry; Imamoglu, Y., Dragutan, V., Karabulut, S., Eds.; Springer Netherlands: Dordrecht, 2007, p 137-150.

(32) Schwab, P.; Grubbs, R. H.; Ziller, J. W. Synthesis and Applications of $\mathrm{RuCl} 2\left(\mathrm{CHR}^{\circ}\right)(\mathrm{PR} 3) 2$ : The Influence of the Alkylidene Moiety on Metathesis Activity. J. Am. Chem. Soc. 1996, 118, 100-110.

(33) Wang, H.-Y.; Yim, W.-L.; Guo, Y.-L.; Metzger, J. O. ESI-MS Studies and Calculations on Second-Generation Grubbs and Hoveyda-Grubbs Ruthenium Olefin Metathesis Catalysts. Organometallics 2012, 31, 1627-1634. 
Table of Contents artwork

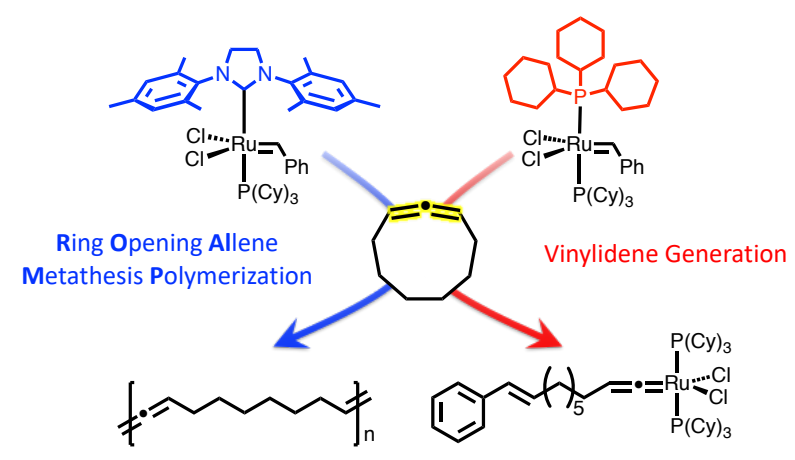

7 